\title{
Mixed Crude Glycerin in Laying Hen Diets: Live Performance and Egg Quality and Fatty Acid Profile
}

http://dx.doi.org/10.1590/1516-635x1604351-358

\section{-Author(s)}

Duarte CRA'

Murakami $A E^{\prime}$

Boso KMO

Eyng C"

Ospina-Rojas IC'

Matumoto-Pintro PT

Departamento de Zootecnia, Universidade Estadual de Maringá, Av. Colombo, 5790 Bloco j45,Maringá, Paraná, 87020-900, Brazil.

" Departamento de Agronomia, Universidade Federal da Grande Dourados, Rodovia Dourados - Itahum, km 12, Cidade Universitária, Dourados, Mato Grosso do Sul, 79804970, Brazil.

III Departamento de Agronomia, Universidade Estadual de Maringá, Av. Colombo, 5790 Bloco j45,Maringá, Paraná, 87020-900, Brazil.

\section{-Mail Address}

Corresponding author e-mail address Alice Eiko Murakami, Departamento de Zootecnia, Universidade Estadual de Maringá, Av. Colombo, 5790 Bloco j45,Maringá, Paraná, 87020-900, Brazil. Phone: +55 44 3011-8942

E-mail: aemurakami@uem.br

\section{Eeywords}

Excreta moisture, eggs, fatty acids, glycerin, glycerol, lipid profile.

\section{ABSTRACT}

This study evaluated the performance and the quality and fatty acid profile of eggs from laying hens fed diets containing mixed crude glycerin (MCG; $80 \%$ vegetable fat $+20 \%$ animal fat). A total of 240 39-week-old Hy-Line W36 laying hens were distributed according to a completely randomized experimental design into six treatments consisting of graded MCG dietary inclusion levels $(0,1.5,3.0,4.5$, 6.0 , and $7.5 \%)$, with five replicates of eight birds each. Feed intake linearly decreased $(p<0.05)$ with increasing MCG inclusion levels. The percentages of myristic, palmitic, and $\alpha$-linolenic acids in the eggs linearly decreased as MCG dietary levels increased $(p<0.05)$, while $\alpha$-linoleic acid, polyunsaturated fatty acids (PUFA) and $\omega-6 / \omega-3$ ratio linearly increased. Excreta moisture linearly increased with increasing levels of MCG inclusion ( $p<0.05$ ). MCG may be included in up to $7.5 \%$ in layer feeds without impairing performance or egg quality, but levels up to $5.54 \%$ reduce SFA egg content. However, the inclusion of MCG in layer diets increases $\omega-6 / \omega-3$ ratio in the eggs.

\section{INTRODUCTION}

Crude glycerin is a byproduct of biodiesel production and has recently become more available due to the increasing production of biodiesel for the replacement of fossil fuels aiming at reducing the environmental impact of the latter. Vegetable oils and animal fats can be used for biodiesel production, and the glycerin is commonly produced by triglyceride transesterification of these raw materials.

Crude glycerin is composed of water, ash, fatty acids, proteins, and methanol. Its primary component is glycerol, which accounts for approximately 80 to $90 \%$ of crude glycerin composition. In the body, glycerol is derived from the lipolysis of the adipose tissue and it is involved in energy metabolism for the processes of gluconeogenesis, lipogenesis, and oxidation to produce energy through glycolysis and the citric acid cycle (Rosebrough et al., 1980). In the diet, glycerol is generated from triacylglycerides in dietary fat. Crude glycerol or glycerol resulting from digestion of triacylglycerides is passively and actively absorbed in the intestine (Kato et al., 2004; Ohta et al., 2006) and transported to the liver by the bloodstream (Bernardino et al., 2014).

Due to the importance of glycerin in energy metabolism and its high availability from biodiesel production, its inclusion in animal diets has generated interest. Several authors have shown that glycerin has a high energy value for poultry (Dozier et al., 2008; Lammers et al., 2008; Dozier et al., 2011; Jung \& Batal, 2011; Lima et al., 2012) regardless of compositional differences resulting from fat sources processing methods, and reagents used for biodiesel production. Most studies suggest supplementing diets with up to $5 \%$ glycerin to maintain or 
improve broiler performance. However, McLea et al. (2011) showed that feeding up to $10 \%$ glycerin to broilers up to 14 days of age and $6.7 \%$ glycerin up to 28 days of age improved live performance.

Lammers et al. (2008) showed that crude glycerin from biodiesel production contains 3,805 kcal apparent metabolizable energy (AMEn)/kg for laying hens, and that $15 \%$ dietary glycerin does not compromise feed intake, egg production, or egg quality. According to those authors, the high sodium content in glycerin may cause a problem because it may result in higher excreta moisture.

In addition to its use as an energy source, the inclusion of glycerin in poultry diets could also be considered due to its high fatty acid levels, which may improve egg lipid profiles. Enriching eggs with $\omega-3$ fatty acids can promote human health by reducing the incidence of cardiovascular disease, cancer and diabetes, among other conditions. Enriching eggs with flaxseed and fish oil has been proposed, but these ingredients are not viable due to the high cost of feed when such ingredients are added. Yalçin et al. (2010) showed that including $7.5 \%$ glycerol in the laying hen diets increased feed and egg linolenic acid concentrations by $15.8 \%$ and $38.9 \%$, respectively.

Therefore, the objective for this study was to evaluate the inclusion of a mixed crude glycerin (MCG) derived from the production of biodiesel consisting of $80 \%$ vegetable oil and $20 \%$ animal fat in laying hens diet on performance parameters, egg quality and fatty acid profile, and excreta moisture.

\section{MATERIALS AND METHODS}

\section{Birds and management}

In total, 240 39-week-old Hy-Line W36 laying hens were distributed according to a completely randomized experimental design into six treatments, consisting of six levels of dietary mixed crude glycerin (MCG; $0,1.5$, $3.0,4.5,6.0$, and $7.5 \%$ ), with five replicate cages of eight birds each. Birds were housed in galvanized wire cages $(25 \times 40 \times 45 \mathrm{~cm})$ divided into four section with two birds each (eight birds per cage). The experiment lasted 112 days and was divided into four 28-day cycles.

The experimental protocol was approved and the birds were maintained in accordance with the guidelines of the Ethics Committee on Animal Use in Experimentation (CEAE/UEM) of the Universidade Estadual de Maringá (UEM, Maringá, Paraná, Brazil).

\section{Diets}

The diets were formulated according the recommendations of the management manual for laying hens during laying (Hy-Line, 2009). The diets were based on soybean meal and corn, and were isonutritious and isoenergetic (Table 1). The glycerin was derived from biodiesel produced from a mixture of $80 \%$ soybean oil and 20\% animal fat, and was supplied by the company Biopar (Rolândia, Paraná, Brazil). Appropriate amounts of glycerin for each diet were first mixed with soybean meal and then added to the other dietary ingredients to obtain a homogeneous diet.

Table 1 - Ingredients and nutritional composition of the experimental diets (as-fed basis).

\begin{tabular}{|c|c|c|c|c|c|c|}
\hline \multirow[b]{2}{*}{ Ingredient kg } & \multicolumn{6}{|c|}{ Mixed crude glycerin levels (\%) } \\
\hline & Control & 1.5 & 3.0 & 4.5 & 6.0 & 7.5 \\
\hline Corn & 62.41 & 60.29 & 58.16 & 56.04 & 53.92 & 51.79 \\
\hline Soybean meal $45 \%$ & 22.47 & 22.88 & 23.28 & 23.68 & 24.07 & 24.48 \\
\hline Soybean oil & 2.64 & 2.87 & 3.10 & 3.32 & 3.55 & 3.78 \\
\hline Dicalcium phosphate & 2.11 & 2.11 & 2.12 & 2.12 & 2.12 & 2.12 \\
\hline Limestone & 9.39 & 9.38 & 9.38 & 9.37 & 9.37 & 9.37 \\
\hline $\mathrm{NaCl}$ & 0.23 & 0.23 & 0.23 & 0.24 & 0.24 & 0.24 \\
\hline Sodium bicarbonate & 0.26 & 0.26 & 0.26 & 0.26 & 0.26 & 0.26 \\
\hline Min.-vitam. supplement. ${ }^{1}$ & 0.25 & 0.25 & 0.25 & 0.25 & 0.25 & 0.25 \\
\hline DL-Met 98\% & 0.18 & 0.18 & 0.18 & 0.19 & 0.19 & 0.19 \\
\hline L-Lys $\mathrm{HCl} 78.5 \%$ & 0.06 & 0.05 & 0.04 & 0.03 & 0.03 & 0.02 \\
\hline Glycerin & 0.0 & 1.5 & 3.0 & 4.5 & 6.0 & 7.5 \\
\hline \multicolumn{7}{|l|}{ Calculated composition } \\
\hline ME (kcal/kg) & 2,860 & 2,860 & 2,860 & 2,860 & 2,860 & 2,860 \\
\hline $\mathrm{CP}(\%)$ & 15.50 & 15.50 & 15.50 & 15.50 & 15.75 & 15.50 \\
\hline Calcium (\%) & 4.20 & 4.20 & 4.20 & 4.20 & 4.20 & 4.20 \\
\hline Chloride (\%) & 0.19 & 0.19 & 0,18 & 0,19 & 0,19 & 0,19 \\
\hline Potassium (\%) & 0.59 & 0.60 & 0,60 & 0,60 & 0,61 & 0,61 \\
\hline Sodium (\%) & 0.18 & 0.18 & 0,18 & 0,18 & 0,18 & 0,18 \\
\hline Available phosphorus (\%) & 0.48 & 0.48 & 0.48 & 0.48 & 0.48 & 0.48 \\
\hline Digestible Lys (\%) & 0.75 & 0.75 & 0.75 & 0.75 & 0.75 & 0.75 \\
\hline Digestible Met+Cys (\%) & 0.63 & 0.63 & 0.63 & 0.63 & 0.63 & 0.63 \\
\hline Digestible Thr (\%) & 0.52 & 0.52 & 0.52 & 0.52 & 0.53 & 0.52 \\
\hline Digestible Trp (\%) & 0.16 & 0.16 & 0.16 & 0.17 & 0.17 & 0.17 \\
\hline \multicolumn{7}{|c|}{$\begin{array}{l}\text { 'The vitamin and mineral supplement contained per kg of diet: vitamin } \mathrm{A}: 20,000 \mathrm{IU} \text {; } \\
\text { vitamin } \mathrm{D}_{3}: 5,500 \mathrm{IU} \text {; vitamin E: } 15.5 \mathrm{mg} \text {; vitamin } \mathrm{K}_{3}: 5 \mathrm{mg} \text {; vitamin } \mathrm{B} 1: 5 \mathrm{mg} \text {; vitamin } \\
\mathrm{B}_{2}: 7.5 \mathrm{mg} \text {; vitamin } \mathrm{B}_{\mathrm{B}}: 15 \mathrm{mg} \text {; vitamin } \mathrm{B}_{12}: 25 \mu \mathrm{\mu g} \text {; Calcium pantothenate: } 15 \mathrm{mg} \text {; Niacin: } \\
62.5 \mathrm{mg} \text {; folic acid: } 1 \mathrm{mg} \text {; Se: } 0.25 \mathrm{mg} \text {; Mn: } 162.5 \mathrm{mg} \text {; Fe: } 100 \mathrm{mg} \text {; Cu: } 25 \mathrm{mg} \text {; Zn: } 125 \\
\text { mg; l: } 2.5 \mathrm{mg} \text {. }\end{array}$} \\
\hline
\end{tabular}

The fatty acid profiles of the glycerin product and of the control diet were determined at the Department of Chemistry and Physics of the Universidade Estadual de Maringá, and are given in Table 2. The physicochemical characteristics, determined at the Technology Institute of Paraná (Instituto de Tecnologia do Paraná - TECPAR, Brazil) and at the department of Chemistry and Physics of the Universidade Estadual de Maringá, are shown in Table 3. 
Table 2 - Fatty acid profile (\%) of the control diet and of the mixed crude glycerin (MCG).

\begin{tabular}{lcc}
\hline & Control diet & MCG \\
\hline 14:0 Myristic acid & 0.09 & 0.47 \\
\hline 16:0 Palmitic acid & 12.39 & 16.2 \\
\hline 16:1 n-7 Palmitoleic acid & 0.10 & $<0.1$ \\
\hline 18:00 Stearic acid & 3.12 & 6.77 \\
\hline 18:1 n-9 Oleic acid & 26.15 & 26.69 \\
\hline 18:1 n-7 Vaccenic acid & 1.08 & 1.81 \\
\hline 18:2 n-6 Linoleic acid & 52.04 & 41.06 \\
\hline 18:3 n-3 $\alpha$-Linolenic acid & 0.20 & 4.00 \\
Saturated fatty acids (SFA) & 16.23 & 23.44 \\
Unsaturated fatty acids (USFA) & 83.79 & 73.55 \\
Monounsaturated fatty acids (MUFA) & 27.33 & 28.49 \\
Polyunsaturated fatty acids (PUFA) & 56.46 & 45.06 \\
MUFA/SFA ratio & 1.68 & 1.21 \\
PUFA/SFA ratio & 2.48 & 1.92 \\
\hline
\end{tabular}

The fatty acid profile was determined at the Department of Chemistry and Physics of the Universidade Estadual de Maringá - UEM, Paraná, Brazil.

The glycerin product contained 2,860 $\mathrm{kcal} / \mathrm{kg}$ metabolizable energy, as determined by a previous digestibility assay (data not published).

Table 3 - Physical and chemical characteristics of the mixed crude glycerin (MCG).

\begin{tabular}{|c|c|}
\hline Characteristics & Mixed crude glycerin \\
\hline Gross energy, (kcal/kg) & 5,242 \\
\hline Moisture, (\%) & 5.45 \\
\hline Glycerol, (\%) & 55.45 \\
\hline Crude protein, (\%) & 0.05 \\
\hline Total fatty acids, (\%) & 21.5 \\
\hline Methanol, (\%) & 505 \\
\hline $\mathrm{NGOM}^{1},(\%)$ & 34.48 \\
\hline Ash, (\%) & 4.62 \\
\hline Calcium, (ppm) & 82.33 \\
\hline Phosphorus, (ppm) & 167.51 \\
\hline Potassium, (\%) & 0.023 \\
\hline Sodium, (\%) & 1.990 \\
\hline Chloride, (\%) & 0.350 \\
\hline Magnesium, (ppm) & 30.72 \\
\hline Copper, (ppm) & 0.197 \\
\hline Chromium, (ppm) & 0.177 \\
\hline Iron, (ppm) & 26.51 \\
\hline Zinc, (ppm) & 0.195 \\
\hline Manganese, (ppm) & 0.853 \\
\hline Aluminum, (ppm) & 33.48 \\
\hline Cobalt, (ppm) & 0.475 \\
\hline Lead, (ppm) & 0.487 \\
\hline $\mathrm{pH}$ & 8.55 \\
\hline Density, $\left(\mathrm{kg} / \mathrm{m}^{3}\right)$ & 1.110 \\
\hline \multicolumn{2}{|c|}{$\begin{array}{l}{ }^{1} \mathrm{NGOM} \text { : non-glycerol organic material, defined as } 100-\text { ( } \% \text { glycerol content + water } \\
\text { content } \%+\text { ash content } \%)\end{array}$} \\
\hline \multicolumn{2}{|c|}{$\begin{array}{l}\text { The physicochemical characteristics were determined at the Technology Institute of } \\
\text { Paraná (Instituto de Tecnologia do Paraná - TECPAR, Brazil) and at the Department of } \\
\text { Chemistry and Physics of the Universidade Estadual de Maringá }\end{array}$} \\
\hline
\end{tabular}

\section{Live performance and egg quality}

Egg production was recorded daily per cage with eight hens, and feed intake was recorded every four weeks. Feed conversion ratio was calculated per egg production (feed intake/egg production) and egg mass (feed intake/egg mass).

Eggs were collected from each cage for four days at the end of each cycle to determine egg mass, egg specific gravity, Haugh unit, and eggshell percentage and thickness. Eggs were weighed and their specific gravity was determined using the saline flotation method, as described by Hamilton (1982). Saline solutions with densities of 1.070 to $1.086 \mathrm{~g} / \mathrm{cm}^{3}$ (at $0.004 \mathrm{~g} / \mathrm{cm}^{3}$ increments) were prepared. Three eggs per replicate were collected to determine Haugh units and eggshell weight and thickness. Albumen height was measured using a digital caliper, and the Haugh units were calculated according to Brant \& Shrader (1958). Three eggshell thickness measurements were recorded using a micrometer (Mitutoyo, Tokyo, Japan) with $0.01 \mathrm{~mm}$ precision, and the mean for three measurements was calculated.

\section{Lipid profiles of egg yolks and control feed}

Six eggs were collected per replicate, and the respective yolks were stored in two pools. One pool included yolks from two sets of replicates, and the other pool included yolks from the three remaining sets of replicates. The yolk pools were subsequently frozen to determine their lipid profile using gas chromatography. Total lipids were extracted in methanol:chloroform:water, according to Bligh \& Dyer (1959).

Triacylglycerides were transmethylated using the ISO 5509 method (ISO, 1978) for triacylglyceride transesterification and fatty acid methyl esters were collected. Fatty acid methyl esters were separated using a Trace GC Ultra gas chromatograph (Thermo Fisher Scientific Inc., Suwanee, GA, USA) equipped with a fused-silica capillary column $(100 \mathrm{~m}$ long, $0.25 \mathrm{~mm}$ internal diameter and $0.20 \mu \mathrm{m}$ CP-Sil88; ChromPack, Middelburg, The Netherlands) and flame ionization detector. Column temperature was set at $140^{\circ} \mathrm{C}$ for 10 minutes then increased to $240^{\circ} \mathrm{C}$ at $5^{\circ} \mathrm{C} \mathrm{min}^{-1}$. Injector and detector temperatures were maintained at 220 and $240^{\circ} \mathrm{C}$, respectively. The following gas flow rates were applied: $1.4 \mathrm{~mL} \mathrm{~min}^{-1}$ for the carrier gas $\mathrm{H}_{2} ; 30 \mathrm{~mL} \mathrm{~min}^{-1}$ for the auxiliary gas $\mathrm{N}_{2} ; 30 \mathrm{~mL} \mathrm{~min} \mathrm{~m}^{-1}$ for the combustion gas $\mathrm{H}_{2}$; and $300 \mathrm{~mL} \mathrm{~min}^{-1}$ for synthetic air. The sample split-ratio was 1:100. Peak areas were determined using the normalization method with a CG-300 Integrator- 
Processor (CGS Instrumentação Analítica, São Paulo, SP, Brazil). Peaks were identified by comparing their retention times with fatty acid methyl esters standards (Sigma Aldrich, St. Louis, MO, USA).

\section{Excreta moisture}

Moisture percentage of the excreta of each replicate of eight hens was determined at the end of the fourth cycle. Plastic sheets were placed under the cages for eight hours to collect the excreta. Samples were then weighed and dried in a forced-ventilation oven at $55^{\circ} \mathrm{C}$ for 72 hours and weighed again to determine moisture percentage.

\section{STATISTICAL ANALYSES}

The influence of MCG dietary inclusion levels on the measured parameters was evaluated using regression analysis and analysis of variance followed by Dunnett's test. Data were analyzed using SAEG software (System for Statistical and Genetic Analysis, Universidade Federal de Viçosa, 1997), and probabilities of $p<0.05$ were considered significant.

\section{RESULTS}

\section{Performance and egg quality}

There was a linear decrease in feed intake as glycerin inclusion level increased ( $p<0.05$; Table 4). Feed intake was lower in birds fed diets with 6.0 and $7.5 \%$ of MCG inclusion $(p<0.05)$ compared to the control group. Egg production and feed conversion were not affected by MCG inclusion ( $p>0.05$ ). Egg quality parameters were not affected by MCG at any of the inclusion levels ( $p>0.05$; Table 5).

\section{Fatty acid profile}

Myristic, palmitic, and $\alpha$-linolenic acid percentages in eggs from MCG-fed laying hens linearly decreased with increasing glycerin level ( $p<0.05$; Table 6). Alphalinoleic acid, polyunsaturated fatty acid (PUFAs), and behenic acid percentages, as well as $\omega-6 / \omega-3$ ratio, linearly increased with increasing glycerin levels $(p<0.05)$. Eicosanoic, arachidonic, saturated fatty acid (SFAs) and $\omega-3$ fatty acid percentages presented a quadratic response to glycerin levels $(p<0.05)$ with the lowest values estimated at 4.25, 3.0, 5.54, and 7.38\% $M C G$, respectively. The percentage of $\omega-6$ acid and PUFA/SFA ratio presented a quadratic response to the glycerin level $(p<0.05)$, with highest values calculated at 6.17 and $5.75 \% \mathrm{MCG}$, respectively. The remaining parameters were unaffected by MCG ( $p>0.05)$.

MCG levels of $1.5 \%$ and greater increased $\alpha$-linoleic acid, behenic acid, PUFA, and $\omega-6$ acid percentages compared with the control group. The percentages of both $\alpha$-linolenic and $\omega-3$ acids decreased and $\omega-6 / \omega-3$ ratio increased in the eggs from laying hens fed 3.0\% MCG compared to the control group $(p<0.05)$.

\section{Excreta moisture}

Excreta moisture percentage linearly increased $(p<0.05)$ with increasing glycerin inclusion levels $(0$ : $81.25 \pm 1.02$; 1.5\%: 77.98 $\pm 0.44 ; 3 \%$ : 80.96 \pm 0.64 ; $4.5 \%: \quad 77.92 \pm 0.80 ; \quad 6 \%: \quad 81.82 \pm 0.61 ; \quad 7.5 \%$ : $\left.82.91 \pm 0.88 ; y=79.27+0.319 X, R^{2}=0.19\right)$. The excreta moisture was lower $(p<0.05)$ when laying hens were fed 3.0 and $4.5 \%$ MCG compared with the control group.

Table 4 - Performance of laying hens fed with different levels of mixed crude glycerin (MCG).

\begin{tabular}{lcccc}
\hline MCG level (\%) & Egg Production (\%) & $\begin{array}{l}\text { Feed Intake } \\
(\mathrm{g} / \mathrm{bird} / \mathrm{day})\end{array}$ & $\begin{array}{c}\text { Feed Conversion ratio } \\
(\mathrm{kg} / \mathrm{kg})\end{array}$ & Feed Conversion ratio (kg/dz) \\
\hline Control & $87.88 \pm 0.57$ & $94.31 \pm 0.67$ & $1.757 \pm 0.023$ & $1.322 \pm 0.009$ \\
\hline 1.5 & $88.82 \pm 0.73$ & $92.57 \pm 0.50$ & $1.754 \pm 0.022$ & $1.288 \pm 0.009$ \\
3.0 & $89.84 \pm 0.14$ & $93.14 \pm 0.49$ & $1.691 \pm 0.008^{*}$ & $1.269 \pm 0.008$ \\
4.5 & $87.86 \pm 0.95$ & $93.55 \pm 0.60$ & $1.761 \pm 0.005$ & $1.303 \pm 0.015$ \\
6.0 & $86.79 \pm 0.73$ & $90.83 \pm 0.63^{*}$ & $1.727 \pm 0.017$ & $1.294 \pm 0.015$ \\
7.5 & $88.34 \pm 0.56$ & $91.52 \pm 0.52^{*}$ & $1.723 \pm 0.010$ & $1.283 \pm 0.012$ \\
\hline Regression & $\mathrm{ns}$ & $\mathrm{L}^{1}$ & $\mathrm{~ns}$ & $\mathrm{~ns}$ \\
\hline CV \% & 1.87 & 1.81 & 2.35 & 2.24 \\
\hline
\end{tabular}

$\mathrm{n}=5$ replicates with 8 birds each

* in the same column indicates significant difference from the control group (Dunnett's test, $p<0.05$ );

ns $=$ not significant $(p>0.05)$

$L 1=93.99-0.3569 \times\left(R^{2}=0.60\right)$ 
Table 5 - Egg quality of eggs from laying hens fed with different levels of mixed crude glycerin (MCG).

\begin{tabular}{lccccc}
\hline MCG level (\%) & $\begin{array}{c}\text { Egg Weight } \\
(\mathrm{g})\end{array}$ & $\begin{array}{c}\text { Specific gravity } \\
\left(\mathrm{g} \mathrm{cm}-3 \mathrm{H}_{2} \mathrm{O}\right)\end{array}$ & Haugh Unit & $\begin{array}{c}\text { Eggshell (\%) } \\
(\mathrm{mm})\end{array}$ & $\begin{array}{c}\text { Eggshell Thickness } \\
(\mathrm{m})\end{array}$ \\
\hline Control & $61.29 \pm 0.62$ & $1.081 \pm 0.001$ & $95.74 \pm 0.41$ & $8.84 \pm 0.09$ & $0.412 \pm 0.003$ \\
\hline 1.5 & $60.88 \pm 0.45$ & $1.082 \pm 0.000$ & $95.76 \pm 0.73$ & $8.94 \pm 0.07$ & $0.408 \pm 0.002$ \\
3.0 & $61.79 \pm 0.62$ & $1.081 \pm 0.000$ & $94.22 \pm 0.74$ & $8.77 \pm 0.07$ & $0.405 \pm 0.003$ \\
4.5 & $61.32 \pm 0.38$ & $1.081 \pm 0.001$ & $95.88 \pm 0.53$ & $8.81 \pm 0.13$ & $0.409 \pm 0.004$ \\
6.0 & $62.07 \pm 0.40$ & $1.081 \pm 0.000$ & $95.97 \pm 0.33$ & $8.78 \pm 0.06$ & $0.407 \pm 0.003$ \\
7.5 & $61.04 \pm 0.51$ & $1.081 \pm 0.000$ & $95.36 \pm 0.65$ & $8.81 \pm 0.05$ & $0.405 \pm 0.004$ \\
\hline Regression & $\mathrm{ns}$ & $\mathrm{ns}$ & $\mathrm{ns}$ & $\mathrm{ns}$ & $\mathrm{ns}$ \\
\hline CV\% & 1.82 & 0.08 & 1.40 & 2.01 & 1.63 \\
\hline
\end{tabular}

$\mathrm{n}=5$ replicates with 8 birds each

ns= not significant $(P>0.05)$

\section{DISCUSSION}

The results suggest that the inclusion up to $7.5 \%$ MCG (80\% vegetable oil + $20 \%$ animal fat) in commercial layer diets is feasible. Although feed intake decreased as MCG level increased, egg production and feed conversion ratio did not differ among treatments. Furthermore, egg quality did not change by including up to $7.5 \%$ glycerin in the diet. Therefore, supplementing laying-hen diets with glycerin may be advantageous because this byproduct is inexpensive and highly available due to worldwide increases in biodiesel and glycerin production.

Supplementing poultry feed with glycerin is also justified because dietary glycerin has a high absorption rate (Yang et al. 2012), because glycerin is absorbed both by active and passive processes in the intestine (Kato et al. 2004; Ohta et al. 2006), and is converted into an energy source through multiple metabolic processes. Several authors have shown that up to $5 \%$ glycerin can be included in broiler chicken diets (Cerrate et al. 2006; Kroupa et al. 2011; Alvarenga et

Table 6 - Fatty acid composition (\%) of the yolk of eggs from laying hens fed with different levels of mixed crude glycerin (MCG)

\begin{tabular}{|c|c|c|c|c|c|c|c|c|}
\hline MCG level (\%) & & & & & & & & \\
\hline Fatty acids & Control & 1.5 & 3.0 & 4.5 & 6.0 & 7.5 & Reg & CV\% \\
\hline Myristic & 0.32 & $0.43^{*}$ & 0.32 & 0.34 & 0.33 & 0.31 & $L^{1}$ & 3.76 \\
\hline Palmitic & 28.46 & 27.55 & 26.87 & 26.22 & 26.24 & 26.21 & $L^{2}$ & 8.26 \\
\hline Heptadecanoic & 0.64 & 0.63 & 0.64 & 0.64 & 0.62 & 0.63 & ns & 4.11 \\
\hline Stearic & 10.18 & 10.85 & 10.58 & 10.59 & 10.08 & 10.66 & ns & 3.93 \\
\hline Oleic & 37.59 & 36.46 & 36.13 & 35.47 & 36.43 & 36.54 & ns & 1.53 \\
\hline Linoleic & 17.68 & $19.39^{*}$ & $19.82^{*}$ & $19.92^{*}$ & $20.35^{*}$ & $20.35^{\star}$ & $L^{3}$ & 4.96 \\
\hline Linolenic & 2.23 & 2.18 & $1.65^{*}$ & $1.79^{*}$ & $1.77^{\star}$ & $1.61^{*}$ & $L^{4}$ & 11.46 \\
\hline Eicosanoic & 1.57 & $1.46^{*}$ & $1.37^{*}$ & $1.37^{*}$ & 1.50 & 1.47 & $Q^{5}$ & 4.07 \\
\hline Behenic & 0.67 & $0.78^{*}$ & 0.71 & $0.75^{*}$ & $0.85^{*}$ & $0.87^{\star}$ & $L^{6}$ & 11.63 \\
\hline Arachidonic & 0.20 & $0.17^{*}$ & $0.17^{*}$ & 0.21 & 0.21 & 0.21 & $\mathrm{Q}^{7}$ & 5.39 \\
\hline Lignoceric & 1.68 & 1.65 & 1.69 & 1.46 & 1.82 & 1.89 & ns & 17.07 \\
\hline DHA (cervonic) & 0.12 & 0.12 & 0.12 & 0.12 & 0.12 & 0.12 & ns & 7.34 \\
\hline SFA & 43.53 & 43.35 & 42.18 & 41.37 & 41.44 & 42.05 & $\mathrm{Q}^{8}$ & 3.75 \\
\hline USFA & 57.98 & 58.48 & 58.06 & 57.68 & 59.07 & 59.01 & ns & 1.24 \\
\hline MUFA & 37.76 & 36.62 & 36.29 & 35.63 & 36.61 & 36.71 & ns & 1.53 \\
\hline PUFA & 20.23 & $21.86^{*}$ & $21.77^{\star}$ & $22.05^{*}$ & $22.46^{*}$ & $22.30 *$ & $L^{9}$ & 4.33 \\
\hline MUFA/SFA & 0.87 & 0.84 & 0.86 & 0.86 & 0.88 & 0.87 & ns & 1.64 \\
\hline PUFA/SFA & 0.46 & 0.50 & 0.52 & 0.53 & 0.54 & 0.53 & $\mathrm{Q}^{10}$ & 4.53 \\
\hline$\omega-3$ & 2.34 & 2.30 & $1.77^{\star}$ & $1.88^{*}$ & $1.89 *$ & $1.73^{*}$ & $\mathrm{Q}^{11}$ & 10.48 \\
\hline$\omega-6$ & 17.88 & $19.50 *$ & $20.00^{*}$ & $20.13^{*}$ & $20.57^{\star}$ & $20.57^{*}$ & $\mathrm{Q}^{12}$ & 5.07 \\
\hline$\omega-6 / \omega-3$ ratio & 7.63 & 8.61 & $11.33^{*}$ & $10.77^{*}$ & $10.89 *$ & $11.87^{*}$ & $\mathrm{~L}^{13}$ & 12.00 \\
\hline
\end{tabular}

* in the same column indicates significant difference from the control group (Dunnett's test, $P<0.05) ; n s=$ not significant $(P>0.05) ; L 1-Y=0.366-0.006 X\left(R^{2}=0.19\right) ; L 2-Y=28.50$ $-0.301 X\left(R^{2}=0.84\right) ; L 3-Y=18.39+0.315 X\left(R^{2}=0.77\right) ; L 4-Y=2.165-0.079 X\left(R^{2}=0.70\right) ; Q 5-Y=1.656-0.085 X+0.010 X 2$ (Min. point: 4.25; $\left.R^{2}=0.75\right) ; L 6-Y=0.682+0.024 X$ $\left(R^{2}=0.73\right) ; Q 7-Y=0.193-0.006 X+0.001 X^{2}$ (Min. point: 3.00; $\left.R^{2}=0.47\right) ; Q 8-Y=43.87-0.843 X+0.076 X^{2}$ (Min. point: $\left.5.54 ; R^{2}=0.85\right) ; L 9-Y=20.88+0.234 X\left(R^{2}=0.69\right) ;$ Q10-Y $=0.467-0.023 X-0.002 X^{2}$ (Max point: $\left.5.75 ; R^{2}=0.98\right) ; Q 11-Y=2.377-0.172 X+0.012 X^{2}$ (Min point: 7.38; $R^{2}=0.78$ ); $Q 12-Y=18.08+0.815 X-0.066 X^{2}$ (Max. point: $\left.6.17 ; R^{2}=0.95\right) ; L 13-Y=8.257+0.504 X\left(R^{2}=0.75\right)$. 
al. 2012). However, according to McLea et al. (2011), levels higher than $6.7 \%$ are not recommended most likely due to the saturation of the enzyme glycerol kinase (Doppenberg \& Van der Aar, 2007), which may limit energy production from dietary glycerol. McLea et al. (2011) showed that $6.7 \%$ glycerin increases dietary nutrient utilization; however, feed conversion ratio increases in broiler chickens above this level. While Bernardino et al. (2014) did not observe any saturation of the liver enzyme glycerol kinase with the dietary inclusion of up to $7.0 \%$ glycerin, this enzyme is probably saturated above this level because the inclusion of $10 \%$ glycerin in broiler diets decreases body and breast weight and increases feed conversion ratio (Cerrate et al. 2006).

Despite the evidence showing that glycerin levels higher than 5\% impair broiler performance, the results from the present experiment and several other studies indicate that glycerin levels higher than $5 \%$ are not very detrimental for egg production. The dietary inclusion of $6 \%$ glycerin did not affect egg production or egg quality of laying hens (Swiatkiewicz \& Koreleski, 2009), and in quails, the inclusion up to $10 \%$ glycerol did not affect reproductive performance (Erol et al., 2009). Furthermore, Lammers et al. (2008) showed that including $15 \%$ glycerin in commercial layer diets did not affect their reproductive performance, which was also observed in the present experiment with up to $7.5 \%$ glycerin inclusion. In a similar study, crude vegetable glycerin included in layer diets at levels between 1.5 and $7.5 \%$ improved the egg production percentage and did not affect quality (Boso et al. 2013).

Interestingly, feed intake decreased as glycerol levels increased; however, feed conversion ratio was not negatively affected. Lower feed intake was also reported by Yalçin et al. (2010) when 7.5\% dietary glycerol was fed to laying hens. According to Min et al. (2010), glycerin has a sweet flavor that should stimulate feed intake. However, the decrease in feed intake may be attributed to high water intake, which could promote satiety in birds, as shown by Romano et al. (2014) in broilers fed glycerin.

Egg quality parameters were not affected by the dietary inclusion of MCG, which indicates that up to $7.5 \%$ glycerin can be added to commercial laying hen diets. Similar results were obtained by Yalçin et al. (2010), for between 2.5 and $7.5 \%$ glycerin, as well as by Swiatkiewickz \& Koresleski (2009), who included up to $6 \%$ glycerin in laying hen diets.

Egg fatty acid profile changed with dietary glycerin. PUFA levels linearly increased with increasing glycerin levels. In addition, a linear reduction of SFAs (myristic and palmitic acids) was observed, which suggests that the consumption of these eggs may be beneficial for human health because high SFA levels can induce cholesterol synthesis in humans and, consequently, increase the incidence of cardiovascular disease. However, total SFA levels showed a quadratic response, with lowest calculated values in eggs from hens fed $5.54 \%$ glycerin, probably due to the quadratic response presented by the eicosanoic acid. Due to the higher PUFA levels and the quadratic response of SFAs, the PUFA/SFA ratio also presented a quadratic response, with the highest value estimated for $5.75 \%$ glycerin.

Relative to PUFAs, $\alpha$-linoleic acid egg content linearly increased as glycerin levels increased, and consequently, egg $\omega-6 / \omega-3$ ratio of the eggs increased. This increase was also due to reduced $\alpha$-linolenic acid levels in the eggs. The $\omega-6 / \omega-3$ ratio in the eggs from laying hens fed glycerin is higher than the recommended level for human consumption, which should be as close to 1 as possible in order to reduce the incidence of many chronic diseases (Simopoulos, 2002) and cancer (Simopoulos, 2006). However, the values obtained in the present study (from 7.63 to 11.87) are consistent with the $\omega-6 / \omega-3$ ratios of commercial eggs, which are typically of at least 12 (Petrovic et al., 2012).

In the present study, dietary MCG did not enrich the eggs with $\omega-3$ acid. This acid presented a quadratic response, with the lowest $\omega-3$ values estimated at $7.38 \%$. The increase in $\alpha$-linoleic acid in the eggs may be partially attributed to glycerin because it contains less $\omega-6$ acid (41.06\%; Table 2 ) than soybean oil, which level was increased in the feeds containing glycerin. Soybean oil is an important PUFA source, particularly of $\omega-6$ acid. It contains $54.64 \%$ PUFAs, consequently increasing their content in eggs (Oliveira et al. 2010). However, high $\omega-6$ consumption is also associated with increased risk of cardiovascular disease in humans (Petrovic et al., 2012). Therefore, according to the results of the present study, dietary MCG did not enrich eggs with $\omega-3$, but it did reduce the contents of the main saturated fats responsible for harmful effects on human health.

During biodiesel production, depending on the catalyst, the glycerin generated may contain high levels of sodium and potassium. High dietary sodium and/or potassium levels are associated with glycerin inclusion in poultry diets, and may cause problems because water intake and excretion may increase, consequently increasing excreta moisture. Excreta moisture linearly increased with increasing glycerin levels in the present study. This increase may not necessarily be due to 
glycerin sodium and potassium levels (Table 3), because their levels were similar among the experimental diets (Table 1). The high hygroscopicity of glycerol may explain the increase in water excretion. It was shown that glycerol intake promoted high water intake in broilers (Romano et al., 2014), but this increase was not associated with excreta moisture levels. Lammers et al. (2008) also reported an increase in excreta moisture in laying hens fed 15\% glycerin. On the other hand, neither Yalçin et al. (2010) nor Boso et al. (2013) observed any differences in excreta moisture of laying hens fed 2.5 to $7.5 \%$ glycerin. Such discrepancies are attributed to differences in glycerin composition.

\section{CONCLUSION}

Mixed crude glycerin may be included in commercial laying hen feeds at levels up to $7.5 \%$ without affecting their performance or egg quality. However, glycerin composition should be considered during diet formulation because it may increase excreta moisture. Furthermore, glycerin reduces egg saturated fatty acid levels, which may promote human health, but increases $\omega-6 / \omega-3$ ratio in the eggs.

\section{ACKNOWLEDGMENTS}

This study was funded by CNPq, Brazil.

\section{REFERENCES}

Alvarenga RR, Lima EMC, Zangerônimo MG, Rodrigues PB, Bernardino VMP. Use of glycerine in poultry diets. World's Poultry Science Journal 2012; 68(4):637-644

Bernardino VM, Rodrigues PB, de Paula Naves L, Rosa PV, Zangerônimo MG, Gomide EM, Saldanha MM, Alvarenga RR. Content of plasmatic glycerol and activity of hepatic glycerol kinase in broiler chickens fed diets containing different sources and concentrations of glycerine. Journal of Animal Physiology and Animal Nutrition 2014; 98(2):328337.

Bligh EG, Dyer WJ. A rapid method of total lipid extraction and purification. Canadian Journal of Biochemistry and Physiology 1959; 37(8):911-917.

Boso KMO, Murakami AE, Duarte CRA, Nascimento GR, Matumoto-Pintro PT, Ospina-Rojas IC. Fatty acid profile, performance and quality of eggs from laying hens fed with crude vegetable glycerine. International Journal of Poultry Science 2013; 12(6):341-347

Brant AW, Shrader HL. Equipment and methods for measuring egg quality. Washington, Department of Agriculture (Agricultural Marketing Service, 246), 1958.

Cerrate S, Yan F, Wang Z, Coto C, Sacakli P, Waldroup PW. Evaluation of glycerine from biodiesel production as a feed ingredient for broilers. International Journal of Poultry Science 2006; 5(11):1001-1007.

Doppenberg J, Van der Aar PJ. Applications of rapeseed meal or -expeller and glycerine in diets for nonruminants In: Doppenberg J, Van der Aar
PJ, editors. Biofuels: implications for the feed industry. Wageningen Academic Publishers: Wageningen, 2007. p. 73-87.

Dozier WA, Kerr BJ, Branton SL. Apparent metabolizable energy of crude glycerin originating from different sources in broiler chickens. Poultry Science 2011; 90(11):2528-2534.

Dozier WA, Kerr BJ, Corzo A, Kidd MT, Weber TE, Bregendahl K. Apparent metabolizable energy of glycerin for broiler chickens. Poultry Science 2008; 87(2):317-322.

Erol H, Yalçın S, Midilli M, Yalçın S. The effects of dietary glycerol on growth and laying performance, egg traits and some blood biochemical parameters in quails. Revue de Médecine Vétérinaire 2009 160(10):469-476.

Hamilton RMG. Methods and factors that affect the measurement of egg shell quality. Poultry Science 1982; 61(10):2022-2039.

Hy-Line. Guia de Manejo de poedeira comercial Hy-Line W-36. Brazil. 2009.

ISO - International Organization for Standardization. Animal and vegetable fats and oils - Preparation of methyl esters of fatty acids. Method ISO 5509. 1978

Jung $B$, Batal AB. Nutritional and feeding value of crude glycerin for poultry. 1. Nutritional value of crude glycerin. Journal of Applied Poultry Research 2011; 20(2):162-167.

Kato $T$, Hayashi $Y$, Inoue $K$, Yuasa $H$. Functional characterization of the carrier-mediated transport system for glycerol in everted sacs of the rat small intestine. Biological \& Pharmaceutical Bulletin 2004; 27(11):18261830.

Kroupa L, Suchý P, Straková E, Herzig I. Glycerol as source of energy in broiler chicken fattening. Acta Veterinaria Brno 2011; 80:157-164.

Lammers PJ, Kerr BJ, Honeyman MS, Staldre K, Dozier WA, Weber TE, Kidd MT, Bregendahl K. Nitrogencorrected apparent metabolizable energy value of crude glycerol for laying hens. Poultry Science 2008; 87(1):104-107.

Lima EM, Rodrigues PB, Alvarenga RR, Bernardino VM, Makiyama L, Lima RR, Cantarelli VS, Zangerônimo MG. The energy value of biodiesel glycerine products fed to broilers at different ages. Journal of Animal Physiology and Animal Nutrition 2012; doi: 10.1111/j.14390396.2012.01335.x.

McLea L, Ball ME, Kilpatrick D, Elliott C. The effect of glycerol inclusion on broiler performance and nutrient digestibility. British Poultry Science 2011; 52(3):368-375

Min YN, Yan F, Liu FZ, Coto C, Waldroup PW. Glycerin - A new energy source for poultry. International Journal of Poultry Science 2010; 9(1):1-4

Ohta KY, Inoue K, Hayashi Y, Hiroaki Y. Carrier-mediated transport of glycerol in the perfused rat small intestine. Biological \& Pharmaceutical Bulletin 2006; 29(4):785-789.

Oliveira DD, Baião NC, Cançado SV, Grimaldi R, Souza MR, Lara LJC, Lana AMQ. Effects of lipid sources in the diet of laying hens on the fatty acid profiles of egg yolks. Poultry Science 2010; 89(11):2484-2490.

Pandalai PK, Pilat MJ, Yamazaki K, Naik H, Pienta KJ. The effects of omega-3 and omega- 6 fatty acids on in vitro prostate cancer growth. Anticancer Research 1996; 16(2):815-820

Petrović M, Gačić M, Karačić V, Gottstein Z, Mazija H, Medić H. Enrichment of eggs in $n-3$ polyunsaturated fatty acids by feeding hens with different amount of linseed oil diet. Food Chemistry 2012; 135(3):1563-1568.

Romano GG, Menten JFM, Freitas LW, Lima MB, Pereira R, Zavarize KC, Dias CTS. Effects of glycerol on the metabolism of broilers fed increasing 
glycerine levels. Brazilian Journal of Poultry Science 2014; 16(1):97106.

Rosebrough RW, Geis E, James P, Ota H, Whitehead J. Effects of dietary energy substitutions on reproductive performance, feed efficiency and lipogenic enzyme activity on Large White turkey hens. Poultry Science 1980; 59(7):1485-1492

Simopoulos AP. The importance of the ratio of omega-6/omega-3 essential fatty acids. Biomedicine \& Pharmacotherapy 2002; 56(8):365-79.

Simopoulos AP. Evolutionary aspects of diet, the omega-6/omega-3 ratio and genetic variation: nutritional implications for chronic diseases. Biomedicine \& Pharmacotherapy 2006; 60(9):502-507.
Swiatkiewicz S, Koreleski J. Effect of crude glycerin level in the diet of laying hens on egg performance performance and nutrient utilization. Poultry Science 2009; 88(3):615-619.

Universidade Federal de Viçosa. Sistema de Análises Estatísticas e Genéticas (SAEG). Versão 5.0 [manual do usuário]. Viçosa (MG); 1997. 150p

Yalçin S, Erol H, Özsoy B, Onbasilar I, Yalçin S, Üner A. Effects of glycerol on performance, egg traits, some blood parameters and antibody production to SRBC of laying hens. Livestock Science 2010; 129(13):129-134.

Yang F, Hanna MA, Sun R. Value-added uses for crude glycerol-a byproduct of biodiesel production. Biotechnology for Biofuels 2012; 5:13. 